\title{
Identification and Characterization of Ectomycorrhizal Cortinarius Species (Agaricales, Basidiomycetes) from Temperate Kashmir Himalaya, India, by ITS Barcoding
}

\author{
Zahoor Ahmad Itoo, ${ }^{1}$ Zafar A. Reshi, ${ }^{1}$ Qussin Basharat, ${ }^{2}$ \\ Sheikh Tahir Majeed, ${ }^{2}$ and Khurshid Iqbal Andrabi ${ }^{2}$ \\ ${ }^{1}$ Biological Invasions Research Lab, Department of Botany, University of Kashmir, Hazratbal, Srinagar 190006, India \\ ${ }^{2}$ Department of Biotechnology, University of Kashmir, Srinagar 190006, India
}

Correspondence should be addressed to Zahoor Ahmad Itoo; zahooritoo151@gmail.com

Received 25 July 2014; Revised 14 November 2014; Accepted 24 November 2014

Academic Editor: Bruno Senger

Copyright ( $) 2015$ Zahoor Ahmad Itoo et al. This is an open access article distributed under the Creative Commons Attribution License, which permits unrestricted use, distribution, and reproduction in any medium, provided the original work is properly cited.

\begin{abstract}
The coniferous forests of Kashmir Himalayas provide a sustainable habitat for wide varieties of ectomycorrhizal fungi. The identification and characterization of many of these fungi however largely involves morphological descriptions of sporocarps alone, thus sometimes raising questions about the authenticity of these studies. The present study was carried out to identify and characterize ectomycorrhizal fungi from the coniferous forests of Kashmir Himalaya using both morphological and molecular methods. Herein we report on the identification and characterization of three potential ectomycorrhizal Cortinarius fungal species, namely, Cortinarius flexipes (Pers. Ex Fr.), Cortinarius fulvoconicus M. M. Moser, and Cortinarius infractus (Pers.) Fr., from Kashmir Himalaya, India, on the basis of their morphological and molecular characterization. Morphological characteristics of all species were measured and compared with standard taxonomic literature. ITS-rDNA (the fungal molecular marker) was used for molecular analysis. The target region of rDNA (ITS1 5.8s ITS2) of these species was amplified using universal fungal primers (ITS1 and ITS4). The sequencing of amplified products and their subsequent blast analysis confirmed the identification of species by comparing the sequences of these species with respective species sequences present in GenBank. Phylogenetic analysis also confirmed the identification of species.
\end{abstract}

\section{Introduction}

Ectomycorrhizas are mutualistic symbiotic associations formed between roots of higher plants with certain soil fungi. The mycorrhizal fungi benefit associated host trees in a number of ways although the most important is by enhancing nutrient mobilization particularly for elements with low mobility in the soil (N and $\mathrm{P}$ ) and several micronutrients, release of nutrients from mineral particles or rock surfaces via weathering, effects on carbon cycling, interactions with mycoheterotrophic plants, mediation of plant responses to stress factors such as drought, soil acidification, toxic metals, and plant pathogens, and rehabilitation and regeneration of degraded forest ecosystems, as well as a range of possible interactions with groups of other soil microorganisms [1-4].
The fungi in return get benefited by receiving $30-60 \%$ of the net photosynthate produced by the host [5]. Worldwide ectomycorrhizal fungi are represented by 343 genera including 11,950 species, of which 252 genera belong to Basidiomycota, 84 to Ascomycota, and 5 to Zygomycota [6].

Cortinarius is one of the largest genera of mushrooms and is represented by more than 2000 ECM species all over the world [7]. Though the genus Cortinarius is very diverse, the species of Cortinarius are usually pretty easy to figure out from other mushroom species due to presence of diagnostic macroscopic characters. Firstly their gills are covered with cortina when young; the tiny fibers of the cortina also form ring zone on the stem. Secondly, the mature gills of Cortinarius mushrooms are usually rusty brown due 
to the presence of rusty brown spores. Though the genus is more or less easy to identify from other genera, the identification of species is one of the most difficult challenges in mushroom mycology, compounded by the fact that there are few comprehensive, current, and reliable keys available for the genus.

The Jammu and Kashmir state located in the far north of India is a mountainous area in the northwest Himalayas that shares international boundaries with Pakistan in the west and China in the northeast. Punjab and Himachal Pradesh are its neighbouring states within the country. The state has a geographic area of $101387 \mathrm{sq}$. km. It lies between $32^{\circ} 17^{\prime}$ and $37^{\circ} 05^{\prime}$ north latitude and $72^{\circ} 31^{\prime}$ and $80^{\circ} 20^{\prime}$ east longitude. The state is divided into three geographic regions: Ladakh, Kashmir Valley, and Jammu. The Kashmir Valley lies between $33^{\circ} 20^{\prime}$ and $34^{\circ} 54^{\prime} \mathrm{N}$ latitude and $73^{\circ} 55^{\prime}$ and $75^{\circ} 35^{\prime}$ E longitudes covering an area of $15,948 \mathrm{sq} . \mathrm{km}$ and harbors diverse coniferous forests. The coniferous forests of Kashmir valley support diverse populations of Pinus, Picea, Cedrus, and Abies which are well known hosts for ectomycorrhizal fungi. The forests in Kashmir support diverse ectomycorrhizal communities and varied ectomycorrhizal sporocarps are found fruiting in these forests during growing season. Earlier workers like Watling and Abraham [8] have reported the occurrence of numerous ectomycorrhizal species from this region. But until now from this region, taxonomic and phylogenetic studies of ectomycorrhizal fungal sporocarps have been based mainly on the analysis and comparison of macroscopic morphological characters like the shape, size, and colour of caps, stalk, and gills. Though morphological characters are of use in identification and characterization of mushroom species but the number of species that can be identified through morphological methods is relatively few and limited. Morphological methods are of no use in discriminating between closely related species and mostly they are helpful in taxonomic identification only up to the genus level in most cases. Molecular methods are currently available to overcome this problem as they exhibit high sensitivity and specificity for identifying fungi at diverse hierarchical taxonomic levels [9].

Together with classical taxonomical methods, molecular methods may be useful and helpful for the correct identification of mushroom species. Through molecular methods most of the fungi have been identified by comparative analyses of the ribosomal DNA sequences, especially the ITS region. For example, Peintner et al. [10] first recorded ectomycorrhizal Cortinarius species from tropical India and established their phylogenetic position using ITS sequences. Itoo et al. [11] characterized and identified Russula firmula and R. postiana from Kashmir Himalaya using analysis of ITS sequence.

In this study, the combined morphological and molecular nucleotide analysis of various Cortinarius species collected from different forest areas of Kashmir Himalaya was used as a tool for their characterization and identification. DNA sequence analysis of the ITS region was performed using the whole ITS region, including ITS1, 5.8S, and ITS2 helping us to identify the Cortinarius species. We used nuclear ribosomal DNA sequences of the internal transcribed spacers (ITS-rDNA) to identify and to investigate the taxonomic and phylogenetic position of these taxa. These sequences have proved to be most useful for molecular systematics of Cortinarius [10, 12] and related genera [13]. For the phylogenetic placement of these species, numerous sequences are available for comparison in GenBank. Our aim was to identify and characterize the field collected Cortinarius species and to address the question of the phylogenetic relationships between these and morphologically similar Cortinarius species.

\section{Materials and Methods}

2.1. Specimen Collection. The ectomycorrhizal sporocarps were collected from different coniferous forest areas of Kashmir Himalaya, like Gulmarg, Kokernag, Daksum, Drang, Mammer, and so forth. The colour of the sporocarps was recorded at the time of collection. Colour of sporocarps was described based on the codes of Kornerup and Wanscher (1978). Standard methods were followed for the collection of sporocarps [14]. Sporocarps were carefully dug out with the help of a knife and photographed in the field. Detailed macromorphological characters of sporocarps, such as colour, shape, size, and odour of sporocarps, were recorded in the field and sample specimens of each type were carried to laboratory in a flat wicker basket for detailed examination. The specimens were examined by standard microscopic techniques in $3 \% \mathrm{KOH}$. Habit and habitat, association pattern, altitude, and forest status were recorded in the field.

2.2. Molecular Characterization. The molecular characterization of sporocarps involved sequencing of internal transcribed spacer (ITS) region of the nuclear ribosomal genes (rDNA). For this, genomic DNA was isolated from sporocarps and roots of collected species.

2.2.1. DNA Extraction. Genomic DNA was isolated from fresh sporocarps by CTAB method. For this $200-250 \mathrm{mg}$ of material was taken and grinded into fine powder with the aid of liquid nitrogen. The powder was then taken in $15 \mathrm{~mL}$ centrifuge tube and to this $5 \mathrm{~mL}$ prewarmed $\mathrm{CTAB}$ buffer $(1 \mathrm{M}$ Tris $\mathrm{HCl} \mathrm{pH}$ 8.0, $5 \mathrm{M} \mathrm{NaCl}, 0.5 \mathrm{M}$ EDTA $\mathrm{pH}$ 8.0, CTAB, $2 \% \beta$-mercaptoethanol) was added. This was then subjected to various steps like addition of chloroform, isopropyl alcohol, phenol, chloroform: isoamyl alcohol, and ribonuclease, and finally extracted DNA pellet was kept in $50 \mu \mathrm{L} \mathrm{TE}$ buffer at $-20^{\circ} \mathrm{C}$. Purified DNA was separated in a $1 \%$ agarose gel stained with ethidium bromide and concentration was estimated by comparison with known length standards.

2.2.2. PCR Analysis. The ITS region of rDNA was amplified by polymerase chain reaction (PCR) with ITS1 and ITS4 primers in Applied Biosystems 2720 Thermal Cycler. The amplified fragment includes ITS1, 5.8S, and the ITS2 of rDNA. The $50 \mu \mathrm{L}$ reaction mixture for PCR amplification contained $2 \mu \mathrm{L}$ template DNA, $5 \mu \mathrm{L}$ PCR buffer, $5 \mu \mathrm{L}$ of $2 \mathrm{mM}$ DNTps, $3 \mu \mathrm{L}$ of each primer, and $0.4 \mu \mathrm{L}$ of Taq polymerase. Amplifications were performed in a thermal cycler with an initial denaturation step of $94^{\circ} \mathrm{C}$ for $5 \mathrm{~min}$ followed by 30 cycles of $94^{\circ} \mathrm{C}$ for $1 \mathrm{~min}, 54^{\circ} \mathrm{C}$ for $1 \mathrm{~min}$, and $72^{\circ} \mathrm{C}$ for 


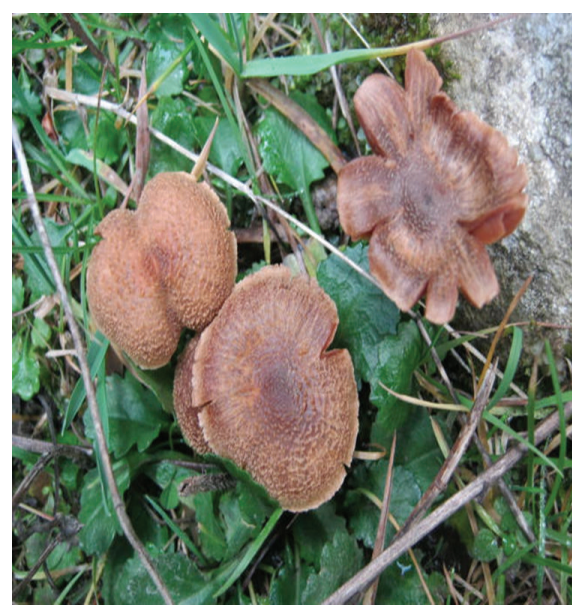

(a) Cortinarius flexipes

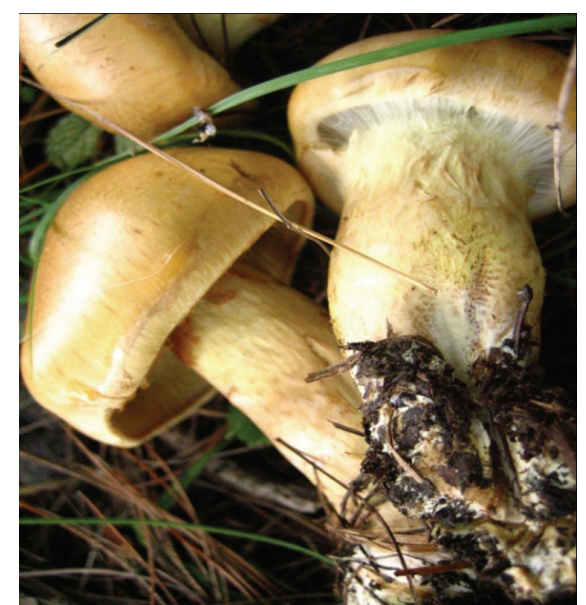

(b) Cortinarius fulviconicus

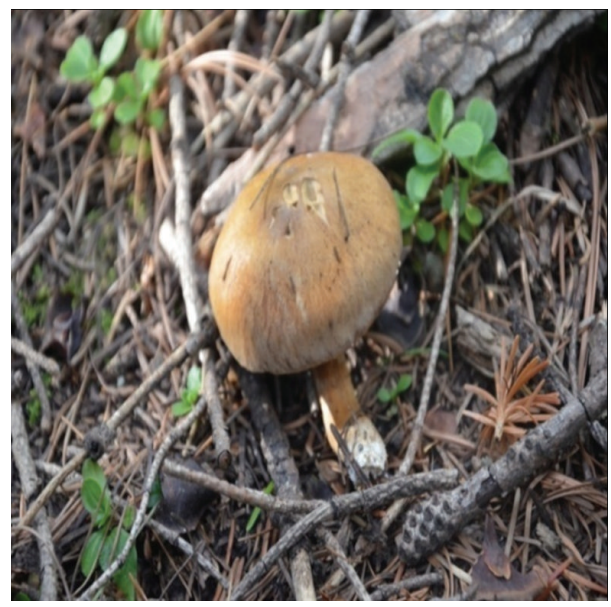

(c) Cortinarius intractus

FIGURE 1: Field photograps of Cortinarius species: (a) Cortinarius flexipes, (b) Cortinarius fulviconicus, and (c) Cortinarius intractus.

$1 \mathrm{~min}$, and a final extension of $72^{\circ} \mathrm{C}$ for $8 \mathrm{~min}$. The purified PCR products of the ITS amplified region were directly sequenced in both directions using the ITS1 and ITS4 pair of amplification primers (SciGenom).

2.2.3. DNA Sequence Assembly and Alignment. The sequenced PCR amplicons were BLAST (Basic Local Alignment Search Tool) searched using the National Center for Biotechnology Information (NCBI), USA, database for comparison of sequences. The initial alignment of all sequences was directly made with the ClustalX multiple alignment program [15]. The alignment was examined and adjusted manually using Microsoft Word on a computer. Manual alignment was facilitated by the use of a colour font.

2.3. Phylogenetic Analysis. For phylogenetic analysis closely related sequences were retrieved from GenBank. The sequence alignments were performed using Molecular Evolutionary Genetics Analysis (MEGA) software [16]. Phylogenetic analysis was conducted on both the ITS and $5.8 \mathrm{~S}$ gene data in neighbor-joining (NJ) method using Clustalx and PHYLIP 3.69 programmes. The programs
DNADIST and NEIGHBOR from PHYLIP 3.69 [17] were used to generate the distance matrix and to produce the tree. Confidence in the branches of the neighbour-joining tree was assessed by bootstrap analysis [18] using 1000 replicates. The programs SEQBOOT, DNADIST, NEIGHBOR, and CONSENSE in the PHYLIP package [17] were used for this purpose.

\section{Results}

Three ectomycorrhizal species from genus Cortinarius were characterized and identified by using morphoanatomical and molecular characterization of sporocarps. The species characterized and identified are Cortinarius flexipes (Pers. ex Fr.), Cortinarius fulvoconicus M. M. Moser, and Cortinarius infractus (Pers.) Fr.

\subsection{Taxonomy}

3.1.1. Cortinarius flexipes (Figure 1(a)). Pileus (Pers. ex Fr.): cap $2-5 \mathrm{~cm}$ broad, shape convex or conical when young, then expanded and umbonate with age, surface subviscid, silky, 
dark brown when moist, especially at the centre, drying pale fawn, covered with minute white fibrous scales; flesh pale orange coloured, no colour change on bruising. Lamellae: gills close and crowded; attachment adnate; dark brown often with violet tinge. Stipe: stem $3-8 \mathrm{~cm}$ long, $1-2 \mathrm{~cm}$ thick at the base, clavate; solid and firm when young, viscid; brownish, covered at first with the white cottony veil which forms a distinct but short-lived ring and cottony scales below. Spores: spores broadly elliptic, spore print rust brown. Habit: naucorioid; growth type: solitary occasionally scattered in coniferous forests.

3.1.2. Cortinarius fulvoconicus (Figure 1(b)). Pileus: cap 5$10 \mathrm{~cm}$ broad; convex or conical when young, with age becomes broadly convex; surface sub viscid, silky, smooth with appressed fibrils over the entire surface, fibrils more towards margin; colour light yellow to orange, with age colour faints; margin incurved, entire, not splitting at maturity; flesh pale orange coloured, no colour change on bruising. Lamellae: gills attached with stem, attachment adnate, space moderate, coloured like the cap, covered with orange coloured cortina when young. Stipe: $2-8 \mathrm{~cm}$ long, $1-2 \mathrm{~cm}$ thick; attachment central; more or less equal; dry; silky; pale orangish above, cream white colored below; fibrillar orange coloured cortina at stipe apex; flesh pale orangish; odor: mild. Habit: naucorioid; growth type: solitary occasionally scattered.

3.1.3. Cortinarius infractus (Pers.) Fr. (Figure 1(c)). Pileus: cap 5-10 cm broad, shape convex, with age becomes broadly convex to flat, or sometimes bell-shaped; surface moist and sticky; margin entire, incurved, splitting at maturity; colour generally grayish when young, with age becomes brown with deep dark brown shades; flesh white, no colour change on bruising or on exposure to air. Lamellae: gills attached with stem, attachment adnate; close; colour light brow to gray, with age becoming rusty brown. Stipe: stem $5-8 \mathrm{~cm}$ long, 2$3 \mathrm{~cm}$ thick; club shaped; surface dry; colour whitish, with age discolouring brownish, occasionally purplish scales preset at apex when young; apex remains adhering with rusty cortina remnants; flesh white and firm. Spores: spore print rusty brown. Habit: naucorioid; growth type: solitary occasionally scattered.

\subsection{Molecular Characterization. The molecular characteri-} zation was performed by carrying out sequencing of rDNA ITS region. The ITS region amplified with ITS1 and ITS4 pair of primers varied in length from 650 to $750 \mathrm{bp}$ in the three species (Figure 2). The ITS region was $650 \mathrm{bp}$ in Cortinarius flexipes and $750 \mathrm{bp}$ in Cortinarius fulvoconicus and Cortinarius infractus. The ITS sequences were subjected to nucleotide sequence alignments using the software ClustalX and sequence comparisons were performed with BLAST network services using National Center for Biotechnology Information (NCBI), USA database for confirmation of their identity. The BLAST result is presented in Table 1. Based on percentage identity and query coverage, the three mushroom species may be identified as follows: accession KC859462 showed 92\% identity with Cortinarius flexipes

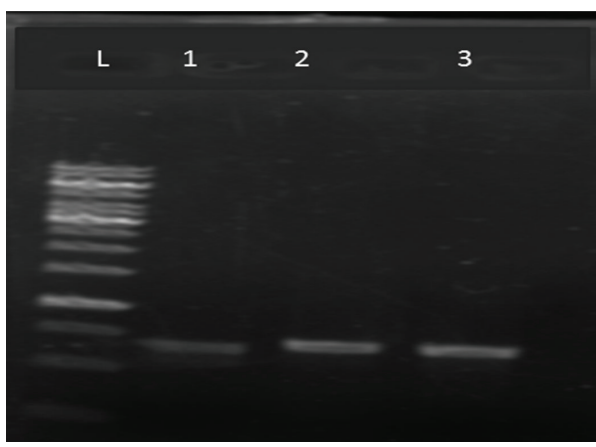

FIGURE 2: $1 \%$ agarose gel showing amplified ITS rDNA PCR products of 3 different ECM Cortinarius species. Samples in each lane are as follows: L, $1 \mathrm{~kb}$ DNA ladder; 1, Cortinarius flexipes; 2, Cortinarius fulvoconicus; and 3, Cortinarius infractus.

(AY669683.1; 90\% coverage); KF023073 showed 99\% identity with Cortinarius fulvoconicus (AY669677.1; 100\% coverage); and KF727563 showed 99\% identity with Cortinarius cf. infractus (FJ039612.1; 100\% coverage). All the three species were identified up to species level from the available GenBank database.

The identity of species was further confirmed by performing phylogenetic analysis of the species in neighbourjoining method. The closely related top matched BLAST sequences with which the present study isolates showed maximum identity were retrieved from GenBank for phylogenetic analysis with present study species accessions. The phylogenetic analysis of the large dataset including 38 ITS sequences of Cortinarius spp. treated resulted in formation of cladogram (Figure 3). The phylogenetic cladogram revealed a close relationship between KC859462 and AY669683.1 (Cortinarius flexipes), KF023073.1 and AY669677.1 (Cortinarius fulvoconicus), and KF727563 and FJ039612.1 (Cortinarius infractus). The identity of species was further confirmed by computing mean pairwise distance. All the three accessions of the present study Cortinarius species showed below 0.004 distances with top matched BLAST searched accession and with which they clustered on parsimony analysis thus confirming their identity (Table 2). Accession KC859462.1 showed 0.000 pairwise distance with AY669683.1 (C. flexipes) (Table 2(a)); accession KF023073.1 showed 0.001 pairwise distance with AY669677.1 (C. fulvoconicus) (Table 2(b)), and accession KF727563.1 showed 0.001 distance with FJ039612.1 (Cortinarius cf. infractus) (Table 2(c)).

\section{Discussion}

The coniferous forests of Kashmir Himalaya support diverse ectomycorrhizal communities due to varied and diverse climatic conditions. The ECM species richness of the region is directly related to its diverse forest communities and weather patterns, but all the regions of the state have not been extensively surveyed and explored for ectomycorrhizal fungi fruiting in different seasons and associated with different host trees till now. Most of the species reported from Kashmir Himalaya have been identified solely on the basis 
TABLE 1: GenBank accession numbers and top BLAST match sequences of the mushroom isolates along with maximum identity, query coverage.

\begin{tabular}{|c|c|c|c|}
\hline \multirow{2}{*}{ Accession number } & \multicolumn{3}{|c|}{ BLAST match sequence } \\
\hline & Reference accession number & Coverage & Maximum identity \\
\hline \multirow{10}{*}{ КC859462 } & AY669683.1 Cortinarius flexipes & 90 & 92 \\
\hline & AF430262.1 Cortinarius sp. & 89 & 90 \\
\hline & JF907921.1 Cortinarius traganus & 88 & 90 \\
\hline & FJ827156.1 Cortinarius clone 3 & 89 & 90 \\
\hline & GQ159816.1 Cortinarius vernus & 86 & 89 \\
\hline & FN428982.1 Cortinarius gallurae & 85 & 89 \\
\hline & AF389156.1 Cortinarius paleaceus & 84 & 85 \\
\hline & EU259284.1 Cortinarius brunneifolius & 84 & 89 \\
\hline & FJ039542.1 Cortinarius sertipes & 80 & 85 \\
\hline & HQ604727.1 Cortinarius fulvescens & 80 & 84 \\
\hline \multirow{10}{*}{ KF023073.1 } & AY669677.1 Cortinarius fulvoconicus & 100 & 99 \\
\hline & FJ039534.1 Cortinarius alnetorum & 99 & 97 \\
\hline & HQ604701.1 Cortinarius cf. umbrinolens & 100 & 97 \\
\hline & HQ604714.1 Cortinarius casimiri & 100 & 97 \\
\hline & FJ039552.1 Cortinarius subsertipes & 100 & 97 \\
\hline & FJ039562.1 Cortinarius canabarba & 100 & 97 \\
\hline & HQ604706.1 Cortinarius cf. subsertipes & 100 & 97 \\
\hline & FJ039551.1 Cortinarius saturninus & 100 & 97 \\
\hline & AY669672.1 Cortinarius psammocephalus & 100 & 97 \\
\hline & AY669658.1 Cortinarius umbrinolens & 100 & 97 \\
\hline \multirow{10}{*}{ KF727563 } & FJ039612.1 Cortinarius cf. infractus & 100 & 99 \\
\hline & HQ604687.1 Cortinarius infractus & 100 & 98 \\
\hline & HQ604688.1 Cortinarius infractus & 100 & 98 \\
\hline & AY669536.1 Cortinarius infractus & 96 & 97 \\
\hline & FJ717596.1 Cortinarius variosimilis & 99 & 94 \\
\hline & HQ604653.1 Cortinarius cinnamomeus & 99 & 94 \\
\hline & FJ717595.1 Cortinarius badiolatus & 99 & 94 \\
\hline & DQ384593.1 Cortinarius phoeniceus & 99 & 94 \\
\hline & FJ039602.1 Cortinarius illumines & 99 & 94 \\
\hline & FJ039601.1 Cortinarius olivaceopictus & 99 & 94 \\
\hline
\end{tabular}

of morphological and microscopic characters. Morphological identification of ECM sporocarps is difficult and requires profound knowledge and experience; it is prone to mistakes due to the frequent homoplasy of phenetic characters. In addition phenotypic variation in fungi can be affected by substrate and environmental factors limiting the application of morphological characters in the identification of ECM sporocarps [19]. Molecular data provides more precise information of the genetic variability of individuals than the phenotypic characters [20].

The combined approach of morphological and molecular biology lets us identify and characterize the field collected ectomycorrhizal sporocarps of three Cortinarius species, namely, Cortinarius flexipes, Cortinarius fulvoconicus, and Cortinarius infractus. We used sequences of ITS as an efficient taxonomic tool to identify ectomycorrhizal fungi from pure basidiocarps collected directly in the field.

The species of Cortinarius were found associated with Pinus wallichiana as the sporocarps were collected under the Pinus wallichiana trees and were found associated with the host roots by tracing out the root system. The association of various Cortinarius species with conifers has also been reported earlier by Watling and Abraham [8]. This was an initial attempt to solve some of the many ambiguities related to the taxonomic classification of Cortinarius species, especially with regard to discriminating among closely related species from this region. Morphological characters are of no use in discriminating between closely related Cortinarius species. The ITS region of fungal ribosomal DNA (rDNA) is highly variable sequence of great importance in distinguishing fungal species by PCR analysis [21, 22]. The highly conserved nature of the ITS sequences makes them an efficient DNA marker for taxonomic and phylogenetic evaluations of the Basidiomycetes. The advantages of using ITS sequences as tool for identification are demonstrated by distinct sequences with high levels of divergence and differentiation, easy amplification, ample type data, and their location between highly conserved regions [23], which 


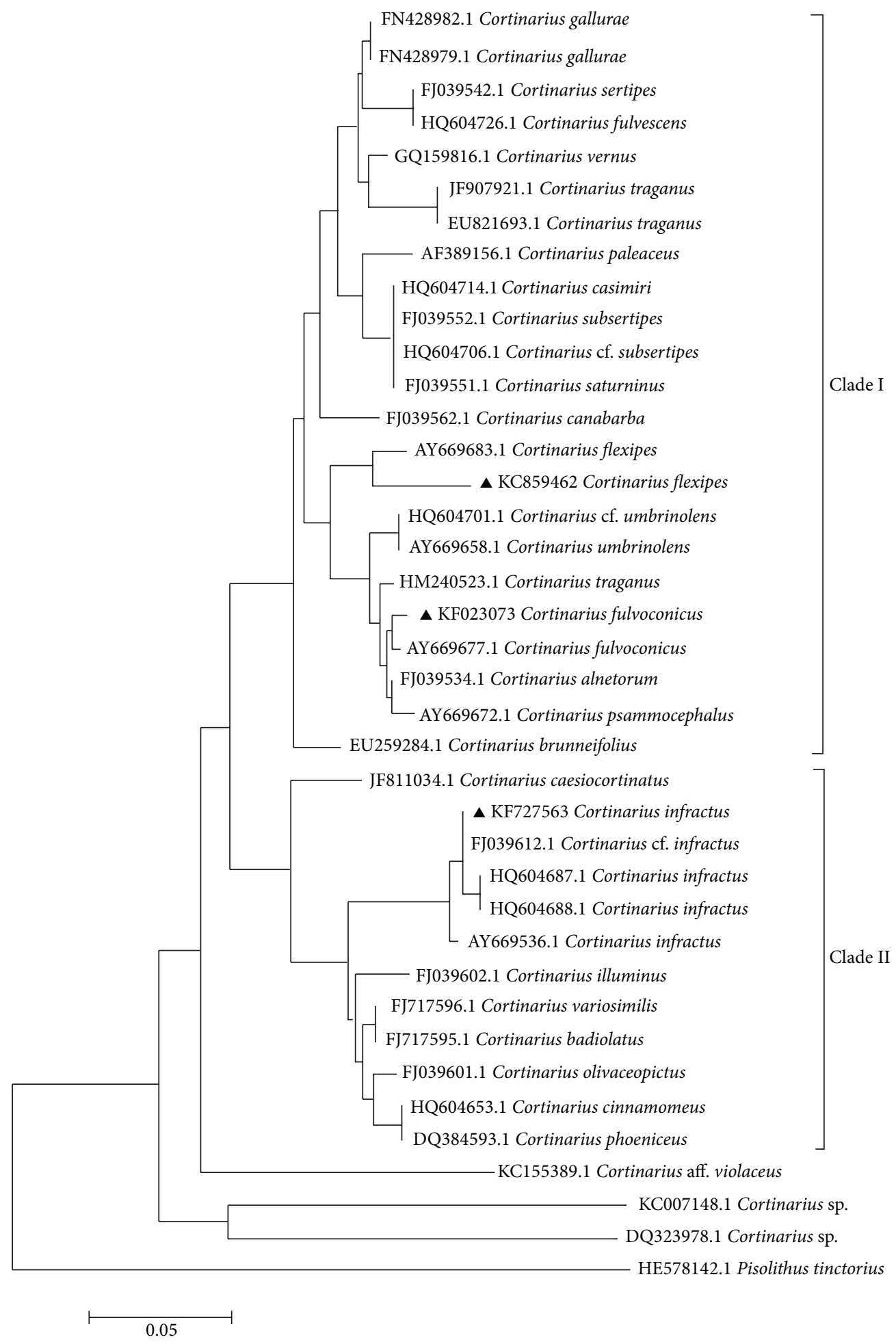

FIgURE 3: Phylogenetic relationship of present study ITS sequences $\boldsymbol{\Delta}$ with other related members based on maximum likelihood method inferred from ITS sequences. Pisolithus tinctorius was used as outgroup.

makes them the superior molecular DNA barcode for the identification of Basidiomycetes at the families and species level.

Analysis of basidiocarps using ITS primers (ITS1 and ITS4 and their derivatives) and PCR analysis had proven very useful and easy method for identifying particular ECM species $[24,25]$. The ITS (ITS1, 5.8S, ITS2) region of the species sequenced varied considerably in length from 650 to $700 \mathrm{bp}$. Phylogenetic analysis of the ITS sequence with other related sequences retrieved from GenBank confirmed their 
TABLE 2: (a) Pairwise nucleotide divergence among the various accessions with which KC859462.1 showed maximum similarity. (b) Pairwise nucleotide divergence among the various accessions with which KF023073.1 showed maximum similarity. (c) Pairwise nucleotide divergence among the various accessions with which KF727563.1 showed maximum similarity.

(a)

\begin{tabular}{|c|c|c|c|c|c|c|c|c|c|c|c|}
\hline \\
\hline \multicolumn{12}{|l|}{$\begin{array}{l}\text { KC859462 } \\
\text { AY669683.1 Cortinarius flexipes }\end{array}$} \\
\hline AF430262.1 Cortinarius sp. & 0.003 & 0.032 & & & & & & & & & \\
\hline JF907921.1 Cortinarius traganus & 0.004 & 0.024 & 0.026 & & & & & & & & \\
\hline HM240523.1 Cortinarius traganus & 0.004 & 0.030 & 0.030 & 0.020 & & & & & & & \\
\hline GQ159816.1 Cortinarius vernus & 0.034 & 0.030 & 0.030 & 0.020 & 0.000 & & & & & & \\
\hline FN428982.1 Cortinarius gallurae & 0.034 & 0.034 & 0.034 & 0.030 & 0.026 & 0.026 & & & & & \\
\hline AF389156.1 Cortinarius paleaceus & 0.034 & 0.030 & 0.030 & 0.020 & 0.000 & 0.000 & 0.026 & & & & \\
\hline EU821693.1 Cortinarius traganus & 0.034 & 0.030 & 0.030 & 0.020 & 0.000 & 0.000 & 0.026 & 0.000 & & & \\
\hline FJ039542.1 Cortinarius sertipes & 0.037 & 0.030 & 0.005 & 0.024 & 0.028 & 0.028 & 0.032 & 0.028 & 0.028 & & \\
\hline FN428979.1 Cortinarius gallurae & 0.032 & 0.024 & 0.026 & 0.000 & 0.020 & 0.020 & 0.030 & 0.020 & 0.020 & 0.024 & \\
\hline HQ604726.1 Cortinarius fulvescens & 0.395 & 0.395 & 0.392 & 0.384 & 0.389 & 0.389 & 0.391 & 0.389 & 0.389 & 0.398 & 0.384 \\
\hline
\end{tabular}

(b)

\begin{tabular}{|c|c|c|c|c|c|c|c|c|c|c|}
\hline KF023073 & & & & & & & & & & \\
\hline AY669677.1 Cortinarius fulvoconicus & 0.001 & & & & & & & & & \\
\hline FJ039534.1 Cortinarius alnetorum & 0.009 & 0.032 & & & & & & & & \\
\hline HQ604701.1 Cortinarius cf. umbrinolens & 0.032 & 0.024 & 0.026 & & & & & & & \\
\hline HQ604714.1 Cortinarius casimiri & 0.034 & 0.030 & 0.030 & 0.020 & & & & & & \\
\hline FJ039552.1 Cortinarius subsertipes & 0.034 & 0.030 & 0.030 & 0.020 & 0.000 & & & & & \\
\hline FJ039562.1 Cortinarius canabarba & 0.034 & 0.034 & 0.034 & 0.030 & 0.026 & 0.026 & & & & \\
\hline HQ604706.1 Cortinarius cf. subsertipes & 0.034 & 0.030 & 0.030 & 0.020 & 0.000 & 0.000 & 0.026 & & & \\
\hline FJ039551.1 Cortinarius saturninus & 0.034 & 0.030 & 0.030 & 0.020 & 0.000 & 0.000 & 0.026 & 0.000 & & \\
\hline AY669672.1 Cortinarius psammocephalus & 0.037 & 0.030 & 0.005 & 0.024 & 0.028 & 0.028 & 0.032 & 0.028 & 0.028 & \\
\hline AY669658.1 Cortinarius umbrinolens & 0.032 & 0.024 & 0.026 & 0.000 & 0.020 & 0.020 & 0.030 & 0.020 & 0.020 & 0.024 \\
\hline
\end{tabular}

(c)

\begin{tabular}{lccccccccccc}
\hline KF727563 & & & & & & & & \\
FJ039612.1 Cortinarius cf. infractus & 0.001 & & & & & & & \\
HQ604687.1 Cortinarius infractus & 0.004 & 0.004 & & & & & & \\
HQ604688.1 Cortinarius infractus & 0.004 & 0.004 & 0.000 & & & & & & \\
AY669536.1 Cortinarius infractus & 0.011 & 0.011 & 0.012 & 0.012 & & & & \\
FJ717596.1 Cortinarius variosimilis & 0.049 & 0.044 & 0.044 & 0.044 & 0.041 & & & & \\
HQ604653.1 Cortinarius cinnamomeus & 0.044 & 0.041 & 0.040 & 0.040 & 0.038 & 0.037 & & & \\
FJ717595.1 Cortinarius badiolatus & 0.047 & 0.043 & 0.042 & 0.042 & 0.039 & 0.016 & 0.034 & & \\
DQ384593.1 Cortinarius phoeniceus & 0.044 & 0.040 & 0.039 & 0.039 & 0.037 & 0.039 & 0.006 & 0.034 & \\
FJ039602.1 Cortinarius illumines & 0.045 & 0.043 & 0.042 & 0.042 & 0.040 & 0.036 & 0.035 & 0.035 & 0.036 \\
FJ039601.1 Cortinarius olivaceopictus & 0.046 & 0.041 & 0.041 & 0.041 & 0.041 & 0.035 & 0.020 & 0.031 & 0.021 & 0.034 \\
\hline
\end{tabular}

identity. Out of the three species characterized Cortinarius flexipes is a new report from Kashmir Himalaya. Peintner et al. [10] recorded ectomycorrhizal Cortinarius species from tropical India and established their phylogenetic position using ITS sequences. Some others have also used a similar technique for identification of ECM species [26, 27]. ITSrDNA the fungal molecular marker in combination with morphoanatomical characters and illustrations is thus a valuable tool for correct identification of ECM species.

\section{Conclusion}

The combined approach of morphological and molecular analysis can enrich and provide additional information to 
mushroom biodiversity and GenBank database and can also lead to the discovery of many new unidentified species from the region.

\section{Conflict of Interests}

The authors declare no financial or nonfinancial conflict of interests.

\section{Acknowledgments}

The authors greatly appreciate Senior and Junior Research Fellowships in favour of Sheikh Tahir Majeed (09/251/0055/ 2013/EMRI) and Qussin Basharat (09/251/0045/2011/EMRI) from Council of Scientific and Industrial Research (CSIR), respectively. Special thanks are due to Sheetal Ambardar (School of Biotechnology University of Jammu) for her help in developing the phylogenetic analysis and providing valuable comments.

\section{References}

[1] S. E. Smith and D. J. Read, Mycorrhizal Symbiosis, Academic Press, London, UK, 3rd edition, 2008.

[2] M. J. Kemppainen and A. G. Pardo, "Nitrogen metabolism in ectomycorrhizal fungi: fHANT-AC gene regulation in Laccaria bicolor," in Current Research, Technology and Education Topics in Applied Microbiology and Microbial Biotechnology, A. Mendez Vilas, Ed., Formatex, 2010.

[3] Z. A. Itoo and Z. A. Reshi, "The multifunctional role of ectomycorrhizal associations in forest ecosystem processes," The Botanical Review, vol. 79, no. 3, pp. 371-400, 2013.

[4] Z. A. Itoo and Z. A. Reshi, "Influence of ectomycorrhizal inoculation on Pinus wallichiana and Cedrus deodara seedlings under nursery conditions," Frontiers in Biology, vol. 9, no. 1, pp. 82-88, 2014.

[5] S. W. Simard, M. D. Jones, D. M. Durall, D. A. Perry, D. D. Myrold, and R. Molina, "Reciprocal transfer of carbon isotopes between ectomycorrhizal Betula papyrifera and Pseudotsuga menziesii," New Phytologist, vol. 137, no. 3, pp. 529-542, 1997.

[6] A. C. Rinaldi, O. Comandini, and T. W. Kuyper, "Ectomycorrhizal fungal diversity: separating the wheat from the chaff," Fungal Diversity, vol. 33, pp. 1-45, 2008.

[7] P. B. Matheny, J. M. Curtis, V. Hofstetter et al., "Major clades of Agaricales: a multilocus phylogenetic overview," Mycologia, vol. 98, no. 6, pp. 982-995, 2006.

[8] R. Watling and S. P. Abraham, "Ectomycorrhizal fungi of Kashmir forests," Mycorrhiza, vol. 2, no. 2, pp. 81-87, 1992.

[9] L. D. Sette, M. R. Z. Passarini, C. Delarmelina, F. Salati, and M. C. T. Duarte, "Molecular characterization and antimicrobial activity of endophytic fungi from coffee plants," World Journal of Microbiology and Biotechnology, vol. 22, no. 11, pp. 1185-1195, 2006.

[10] U. Peintner, M. M. Moser, K. A. Thomas, and P. Manimohan, "First records of ectomycorrhizal Cortinarius species (Agaricales, Basidiomycetes) from tropical India and their phylogenetic position based on rDNA ITS sequences," Mycological Research, vol. 107, no. 4, pp. 485-494, 2003.
[11] Z. A. Itoo, Z. A. Reshi, and K. I. Andrabi, "Characterization and identification of Russula firmula and Russula postiana from Himalayan moist temperate forests of Kashmir," African Journal of Biotechnology, vol. 12, pp. 3643-3647, 2013.

[12] U. Peintner, N. L. Bougher, M. A. Castellano et al., "Multiple origins of sequestrate fungi related to Cortinarius (Cortinariaceae)," American Journal of Botany, vol. 88, no. 12, pp. 21682179, 2001.

[13] J.-M. Moncalvo, F. M. Lutzoni, S. A. Rehner, J. Johnson, and R. Vilgalys, "Phylogenetic relationships of agaric fungi based on nuclear large subunit ribosomal DNA sequences," Systematic Biology, vol. 49, no. 2, pp. 278-305, 2000.

[14] N. S. Atri, A. Kaur, and H. Kaur, "Wild mushrooms-collection and identification," Mushroom Research, vol. 14, pp. 56-59, 2003.

[15] D. G. Higgins, A. J. Bleasby, and R. Fuchs, "CLUSTAL V: improved software for multiple sequence alignment," Computers and Applied Bioscience, vol. 8, pp. 189-191, 1992.

[16] K. Tamura, D. Peterson, N. Peterson, G. Stecher, M. Nei, and S. Kumar, "MEGA5: molecular evolutionary genetics analysis using maximum likelihood, evolutionary distance, and maximum parsimony methods," Molecular Biology and Evolution, vol. 28, no. 10, pp. 2731-2739, 2011.

[17] J. Felsenstein, PHYLIP_Phylogenetic Inference Package, Version 3.5c. Computer Programs Distributed by the Author, Department of Genetics, University of Washington, Seattle, Wash, USA, 1995.

[18] J. Felsenstein, "Confidence intervals on phylogenies: an approach using the bootstrap," Evolution, vol. 39, no. 4, pp. 783-791, 1985.

[19] F. A. Avin, S. Bhassu, T. Y. Shin, and V. Sabaratnam, "Molecular classification and phylogenetic relationships of selected edible Basidiomycetes species," Molecular Biology Reports, vol. 39, no. 7, pp. 7355-7364, 2012.

[20] S. Siddiquee, S. G. Tan, U. K. Yusuf, N. H. N. Fatihah, and M. M. Hasan, "Characterization of Malaysian Trichoderma isolates using random amplified microsatellites (RAMS)," Molecular Biology Reports, vol. 39, no. 1, pp. 715-722, 2012.

[21] A. Nauman, M. Navarro-González, O. Sánchez-Hernández, P. J. Hoegger, and U. Kües, "Correct identification of woodinhabiting fungi by ITS analysis," Current Trends in Biotechnology and Pharmacy, vol. 1, pp. 41-61, 2007.

[22] R. H. Nilsson, E. Kristiansson, M. Ryberg, N. Hallenberg, and K.-H. Larsson, "Intraspecific ITS variability in the kingdom Fungi as expressed in the international sequence databases and its implications for molecular species identification," Evolutionary Bioinformatics, vol. 2008, no. 4, pp. 193-201, 2008.

[23] T. White, T. Bruns, S. Lee, and J. Taylor, "Amplification and direct sequencing of fungal ribosomal RNA genes for phylogenetics," in PCR Protocols: A Guide to Methods and Applications, pp. 315-332, Academic Press, San Diego, Calif, USA, 1990.

[24] C. Kulmann, S. J. Kim, S. S. Lee, and C. Harms, "A reliable 'Direct from Field' PCR method for identification of mycorrhizal fungi from associated roots," Mycobiology, vol. 31, no. 4, pp. 196-199, 2003.

[25] J. S. Lee, M. O. Lim, K. Y. Cho, J. H. Cho, S. Y. Chang, and D. H. Nam, "Identification of medicinal mushroom species based on nuclear large subunit rDNA sequences," Journal of Microbiology, vol. 44, no. 1, pp. 29-34, 2006. 
[26] S. Hortal, J. Pera, L. Galipienso, and J. Parladé, "Molecular identification of the edible ectomycorrhizal fungus Lactarius deliciosus in the symbiotic and extraradical mycelium stages," Journal of Biotechnology, vol. 126, no. 2, pp. 123-134, 2006.

[27] M. Iotti and A. Zambonelli, "A quick and precise technique for identifying ectomycorrhizas by PCR," Mycological Research, vol. 110, no. 1, pp. 60-65, 2006. 

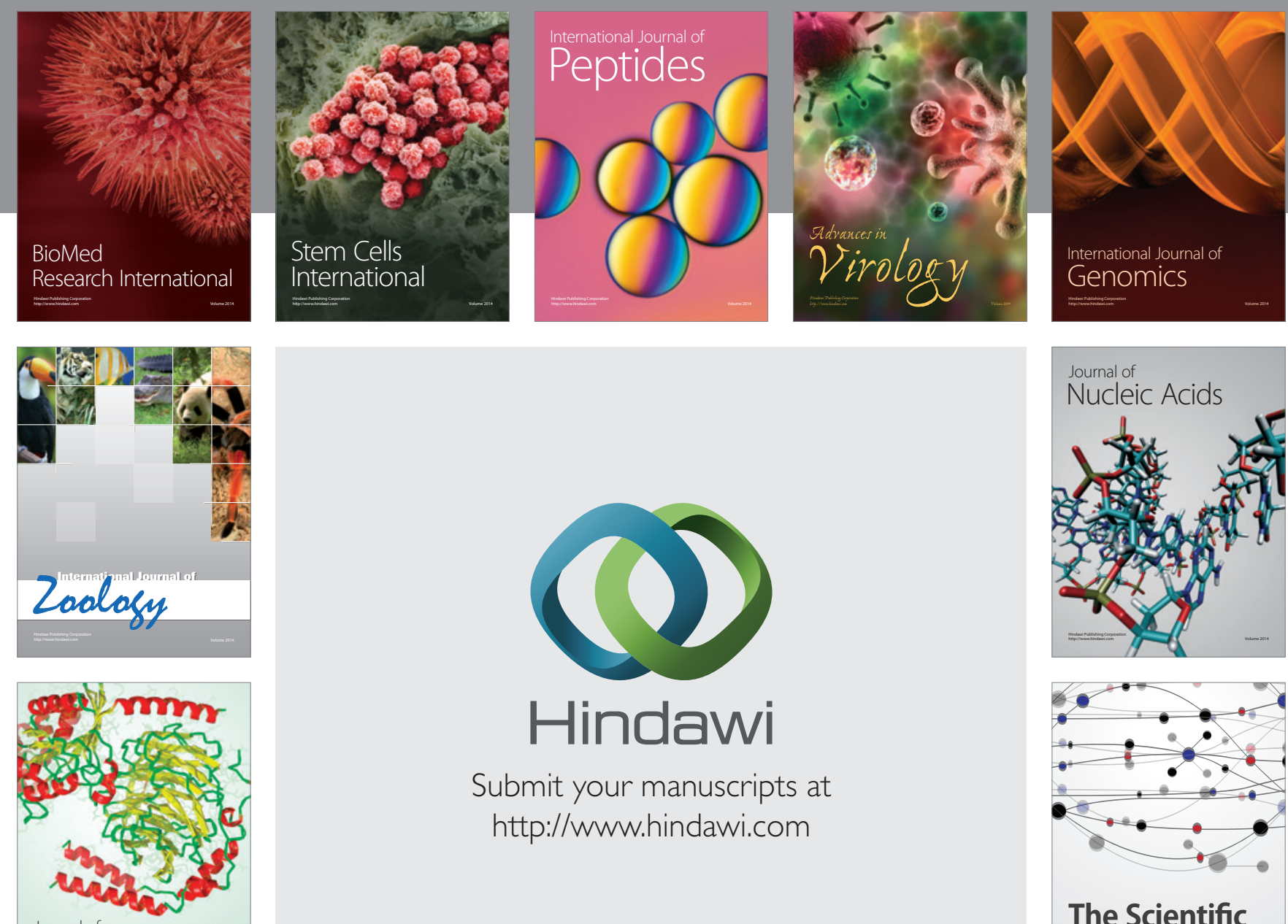

Submit your manuscripts at

http://www.hindawi.com

Journal of
Signal Transduction
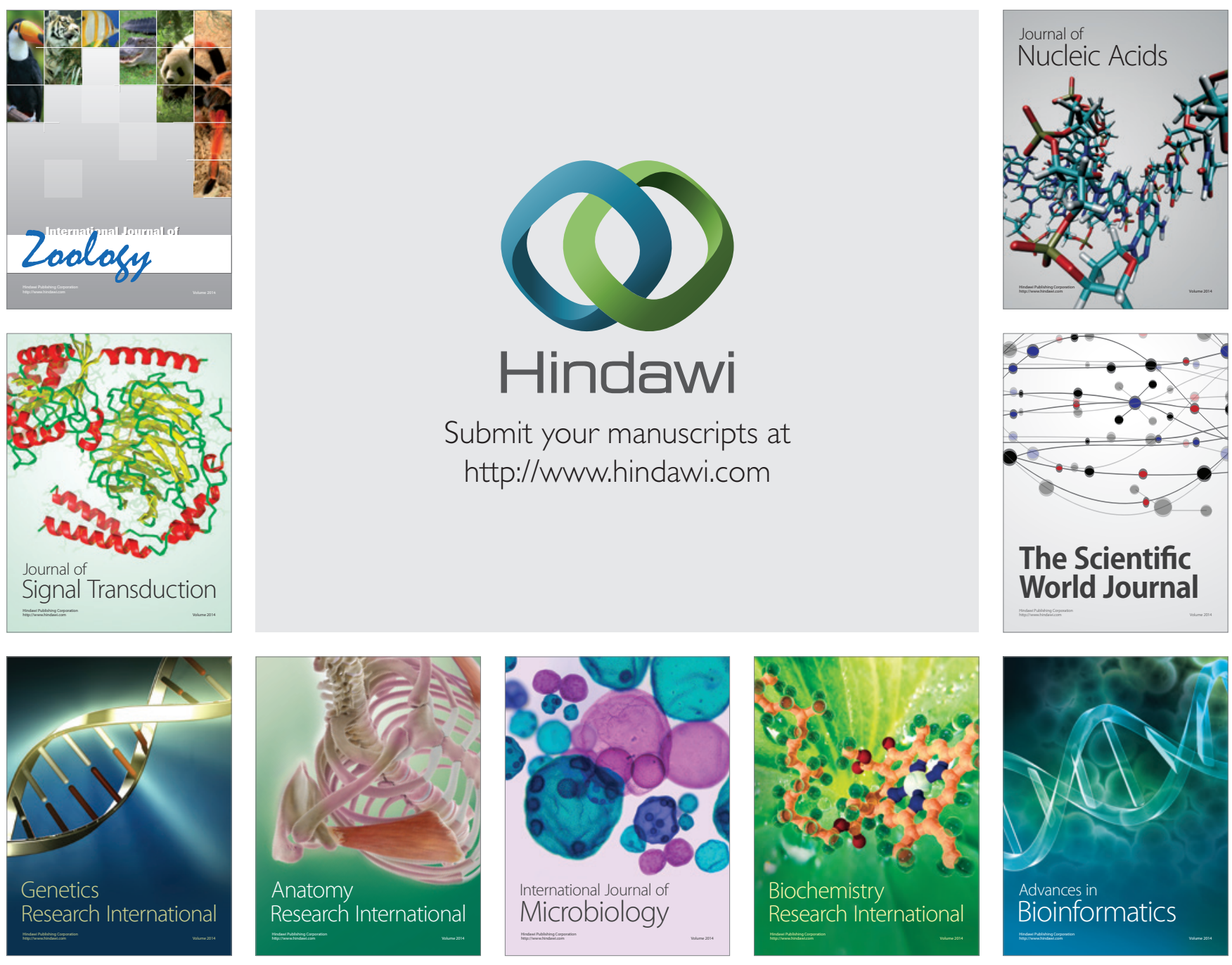

The Scientific World Journal
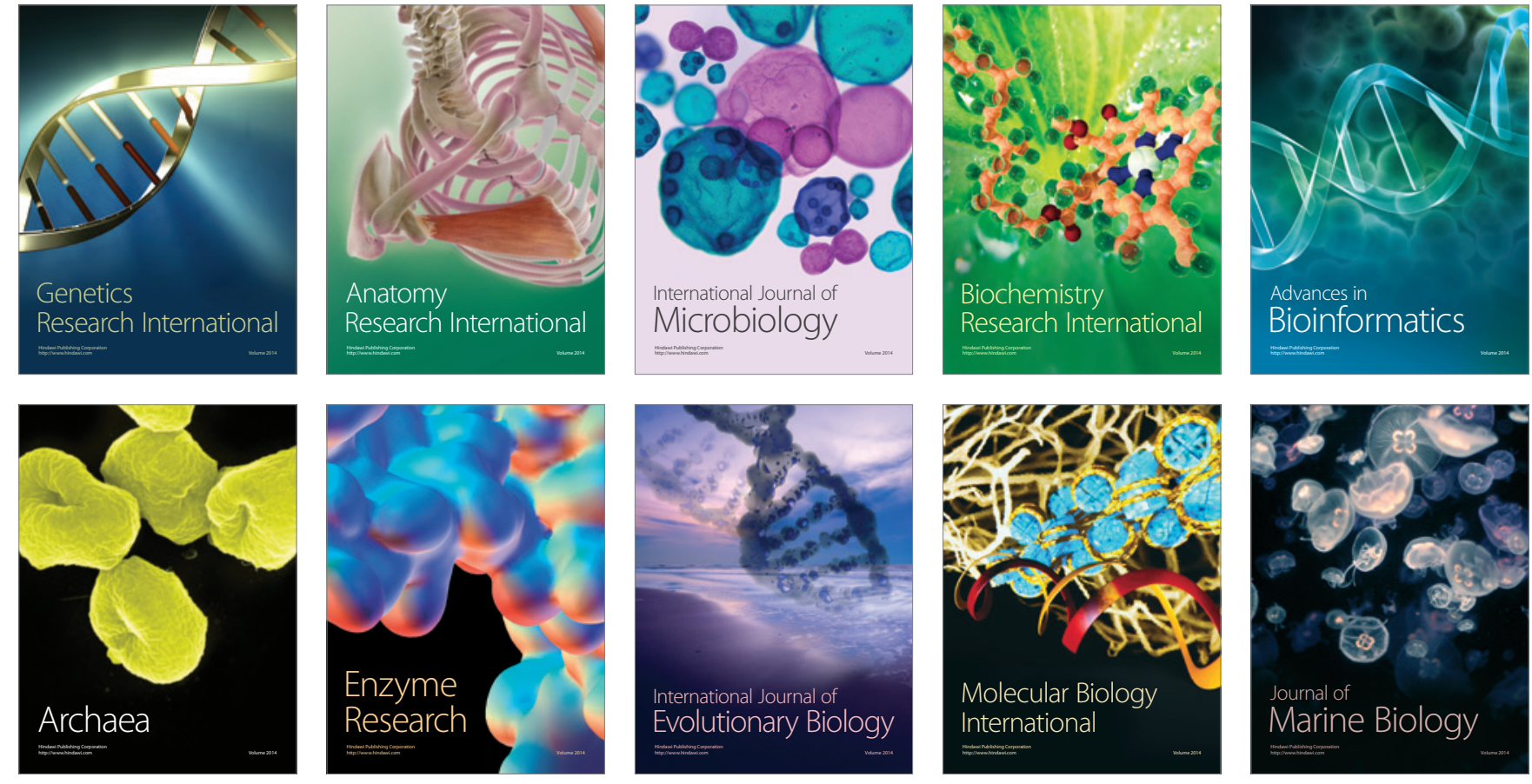